\title{
Applications of Geographic Information System and Remote Sensing in Road Monitoring in Minna and Environs, Nigeria.
}

\author{
Onuigbo I. C., Orisakwe K. U. \\ Department of Surveying and Geoinformatics, Federal University of Technology, Minna, Nigeria. \\ Department of Surveying and Geoinformatics, Federal University of Technology, Yola, Nigeria.
}

\begin{abstract}
The study focused on the use of Geographic Information System (GIS) and Remote Sensing (RS) in road monitoring for maintenance. Data used include satellite imagery of the study area. The acquisition of data used was by field method, remote sensing method and a combination of remote sensing and GIS.Data from field measurements served as input data to the GIS database. Satellite imageries showed current, up-to-date roads, their locations, and other details, including condition, number of lanes and other attributes. GIS was used to create the database of roads and for data processing and analysis. The results showed that GIS and Remote Sensing can be used successfully in road monitoring. The results further demonstrated the efficiency and efficacy of GIS and RS. Adequate recommendations were also made.
\end{abstract}

Key words: GIS, Remote sensing, Imagery, Database, Monitoring

\section{Introduction}

Roads are essential for easy movement of goods and materials, human beings and other movable things. A good road network promotes and accelerates the economic development of any country, through trade, tourism and other commercial developments. Road networks in most African countries are in bad shape; road conditions in the study area are poor at present.

A database on road networks, existing spatial distribution of roads and their possible links to the roads of neighboring places, towns or even countries can be created, and updated, using Remote Sensing and Geographic Information Systems.

The traditional method of road monitoring is by physical inspection; this is tedious, time-consuming, and costly and requires much manpower and materials. It also constitutes danger to the monitoring team, etc. As more and more roads are built, this traditional method can no longer adequately serve the desired purpose. It therefore becomes necessary to introduce modern methods and technologies to monitor our roads. Hence, the study or choice of GIS and Remote Sensing in road monitoring as a better option, using Minna and environs as a case study.

The timely and cost-availability of geoinformation or geographic data is essential for monitoring.

Such data include remote sensing images or satellite imagery. The frequent revisit of each point on the earth's surface by satellites in space is an advantage of satellite imageries. The technology of remote sensing provides a descriptive and analytical way for identifying geographic features. Examples of geo-information materials that can be used for road monitoring include aerial photos, satellite imagery, radar imagery, etc.

Throughout the world, roads carry the bulk of goods and services being traded coupled with people being transported, even where relatively sophisticated alternatives have been created (Horner, 1991). On its journey from the factory to the ultimate consumer, a product may or may not be carried by ship, train or aircraft; it will almost certainly, at some point, travel by lorry or van or humans or animals by road. Roads are both a huge investment and of fundamental importance to the economy, and so the need to monitor them always so that they do not deteriorate to severe or unmanageable conditions become necessary.

Information on the location and condition of road networks is critical to their effective management. New tools are now available to make the infrastructure management process efficient, and /or integrative. Remote Sensing technology is one of these tools.

The research carried out by Lagunzad and Mcpherson (2003) describes how Global Positioning System (GPS), Geographic Information System (GIS) and the traditional database applications will help in the management of the highway network using a common Locational Reference System (LRS) that will integrate all data on road and bridge inventories. GIS provides the mechanism for integrating all of the above data into a single environment and to enable spatial querying and analysis of that data. For now, we typically rely on visual inspection, intuition and occasional spot measurements in the assessment of road conditions; hence, the need to introduce the use of GIS and remote sensing which will be better, faster, and more accurate.

Under-development of a place, country or region, etc. is associated with the fact that the place or region has not been opened up with required transport routes (Egunjobi, 1991). 
Roads are very necessary for the economic development of any place. Roads open up a place and bring in all kinds of developments. The density, orientation and quality of the transportation network are factors of supreme significance influencing the socio-economic development of an area. This study is therefore aimed at exploring the use of GIS and Remote Sensing technologies in road monitoring, using Minna and environs as areas of study.

\section{Area of Study}

Minna and environs is the study area. Minna is the capital of Niger State, one of Nigeria's 36 states. The study area lies between Latitudes $9^{\circ} 31^{1}$ and $9^{\circ} 40^{1}$ North of Equator, and Longitudes $6^{\circ} 29^{1}$ and $6^{\circ} 35^{1}$ East of Greenwich Meridian. In the present political zoning system, it is within the North Central Geopolitical zone of Nigeria, and occupies an area of 884 hectares. It is about 145 kilometers, by road from Abuja, the Federal Capital of Nigeria. Figure 1 below is a satellite image of Minna central.

The extent of the area covered in the study is Minna and environs. And the study is focusing on monitoring of roads to assess their conditions for possible prompt preventive maintenance planning. Actual maintenance work is not included in the study.

Yu, et.al. (2007), studied on how to solve or overcome the shortcomings of the traditional video monitoring system. The paper or research set out to present an efficient road monitoring system based on GIS technology, named Road Monitoring GIS (RMGIS) system. The researchers stated in their introduction that with the development of modern cities, the road traffic flow and other similar matters have increased greatly. For this reason, it was felt that the present situation requires effective integration of a number of new advanced technologies to tap the potential hardware, network and video image resources. The road monitoring GIS (RMGIS) system presented in the said paper uses GIS functions which are combined with computer technology, geographic information technology, network technology and video surveillance technology. According to Yu et.al.(2007), RMGIS is necessary because nowadays, most road monitoring systems can not directly show the precise geospatial location of monitored place. Their (proposed) system makes use of the powerful functions of GIS to realize real-time monitoring and recording road conditions on electronic map in the system center. 


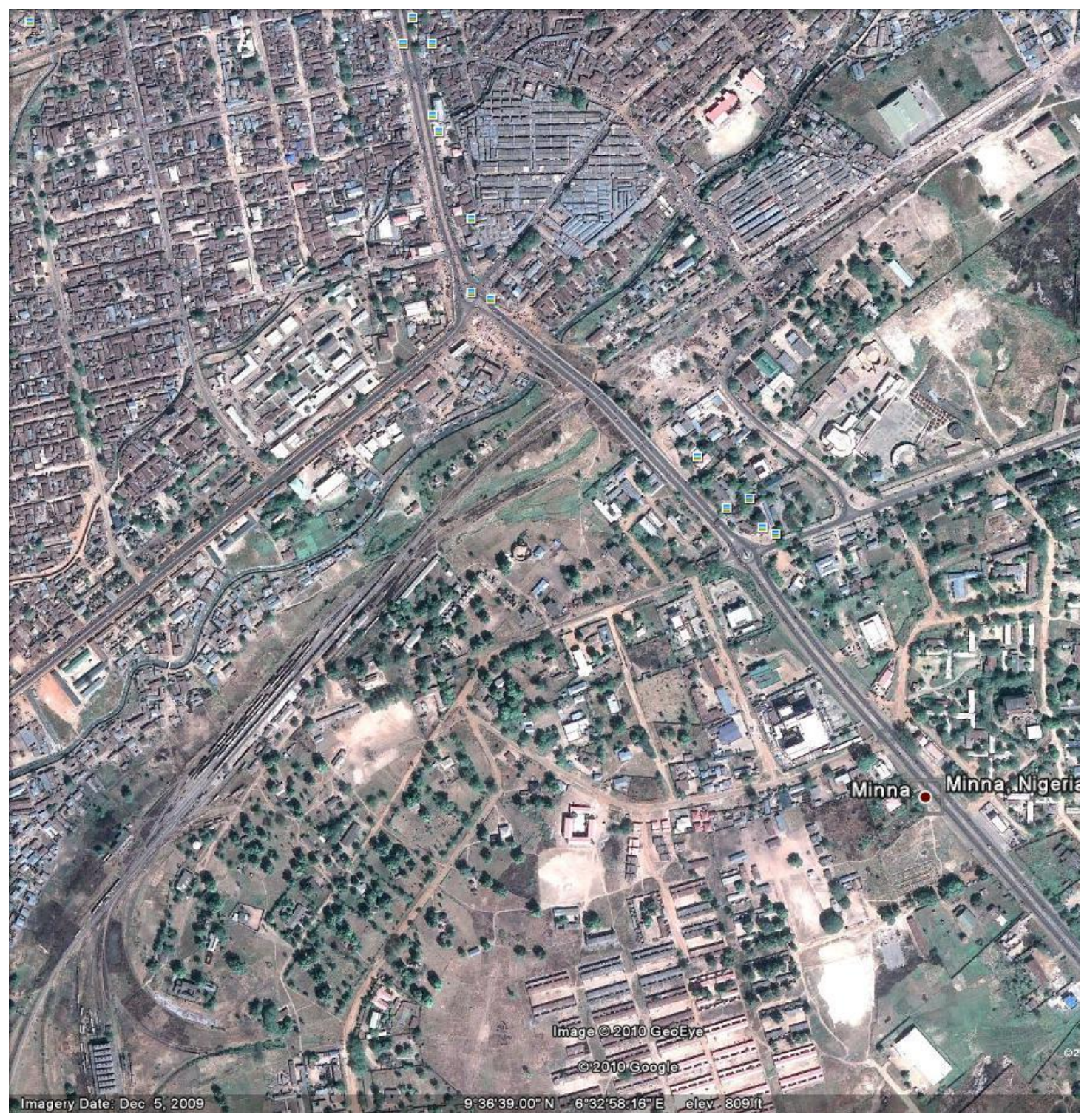

Source: Google Satellite Image

Figure 1: Minna Central Satellite image

The system improves adaptability and avoids the disadvantages of resource-wasting, time-consuming and redundant investment. The system can Query road information, azimuth, and location information.

In another development, Akomolafe et. al. (2009), in their paper, stated that the Geographic Information System (GIS) and the Global Positioning System (GPS) are the two geospatial technologies that are being used in monitoring of transportation generally.

Transportation is a requirement for every nation regardless of its industrial capacity, political stability, population, size or technological development. The most reliable and widely embraced means of transportation is road. They defined Geospatial technology as an electronic system for capturing, storing, retrieval, analyzing and displaying data related to positions on the earth.

The said study was aimed at working out a way of enhancing road monitoring and safety by using geospatial technology. The study was concerned with developing a system that can be adapted to obtain geodetic data of any road. According to it, maps are available to show roads and their connections but they are not comprehensive enough to describe the actual location of any point on these roads. This inadequacy was because the maps are not digitized. It is therefore imperative to device a means by which any point on these 
roads can be located and the accomplishment of this can only be made realistic by the use of geospatial technologies (Akomolafe, et. al. 2009).

The GIS tools were used to perform the five steps of data acquisition, manipulation, pre-processing, management and analysis. The data acquisition entailed the use of the GPS receiver to record the coordinates of these roads. The coordinates are the northings and eastings (in UTM system) which correspond to latitudes and longitudes (Geodetic system). The data were entered into the computer system. Arcview 3.3 software program was used to generate the digitized map of Nigeria road networks. The coordinates of the roads linking the state capitals (in a geodetic system) were taken and entered into the computer system. The second step was the conversion of these coordinates obtained in geodetic system to UTM system. The third major step was georeferencing in which GIS software was applied and Arcview 3.3 was used to geo-reference. Finally it was digitized in order to produce the object map. The researchers succeeded in using GIS techniques to generate a digitized map of Nigeria roads.

\section{Materials and Methods}

The spatial data required for the study was acquired by (1) field method, (2) by remote sensing method, and (3) a combination of remote sensing and GIS. Satellite imageries covering the study area and showing the roads were acquired and used. Data from field work/ measurements served as input data to the GIS database. The satellite imagery used is Quickbird imagery of 2006 acquired from the National Population Commission of Nigeria. It has a resolution good enough for use in the study. The data base of roads in the study area was created using GIS. Ground truthing was conducted to check and verify locations. Georeferencing was carried out to make all the features to be in the same coordinate system. All the data gathered were imported into the GIS package and combined with the database for analysis. Satellite images showed current, up-to-date roads, their locations and other details, including condition, number of lanes, etc. A combination of satellite images and GIS was used to store, analyze, manipulate interpret and create GIS query for the raods.Road conditions are better analyzed in the GIS system.

\section{Results and Discussion}

The roads are clearly seen on the imagery and road surface conditions can be determined from the satellite images. Remote sensing images show clearly details of the roads. Since remote sensing data can be regularly acquired, it is possible at any time to use satellite images to monitor and assess the conditions of roads. Figure 2 shows an overlay of digitized road network on imagery. The roads were clearly identified on the images. Remote sensing made possible the satellite image used in figure 2. GIS was used to digitize the roads and overlay them on the satellite imagery. A good overview of the road network is obtained; these roads can then be monitored, and maintenance planned as necessary. The road network database was generated or created. In the database are the names of roads identified in the study area; their types, and conditions, etc. in figure 3. The study attests to the fact that remote sensing satellite images can capture more information about roads than field surveys can, and can assist in a number of situations. Figure 4 below shows the attribute data used to create the database.

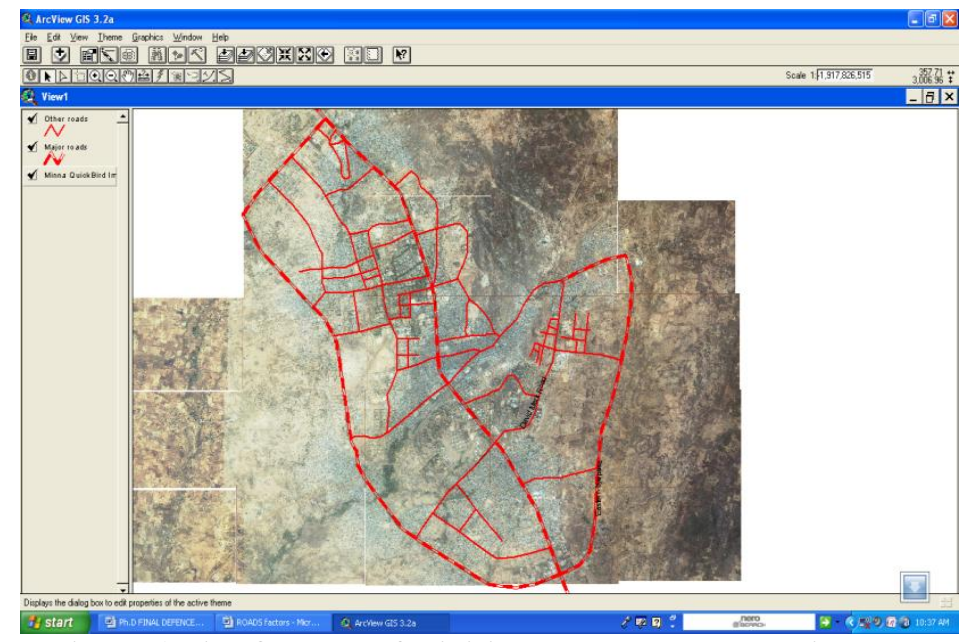

Figure 2: An Overlay of Digitized road network on imagery Source: Authors' work 


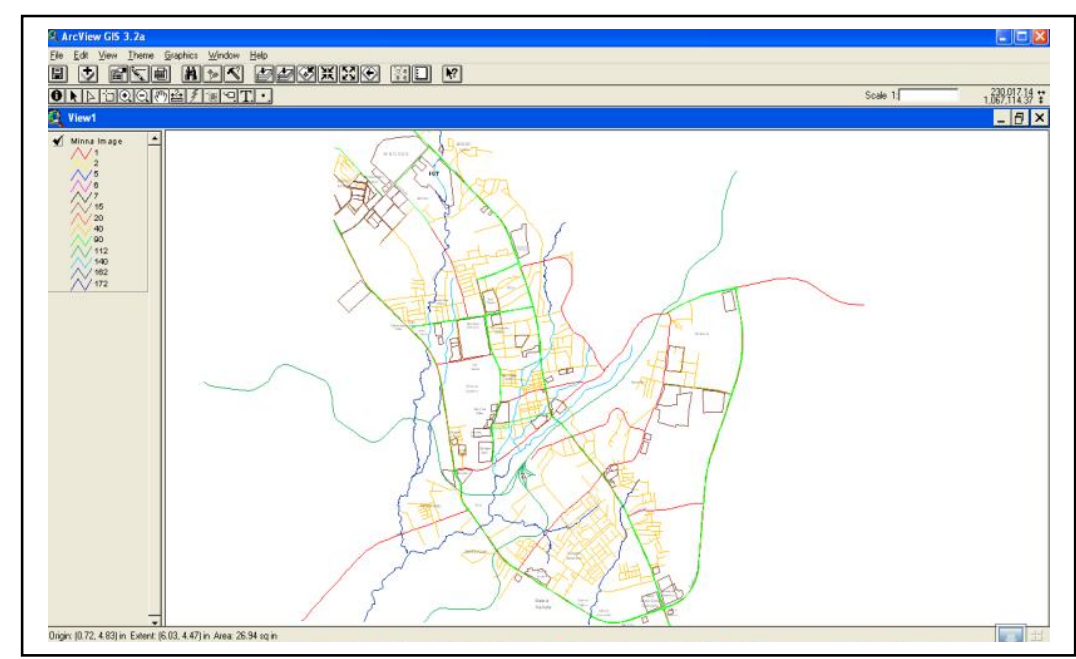

Figure 3: UPDATED ROAD MAP USING GIS AND REMOTE SENSING

\begin{tabular}{|c|c|c|c|c|c|c|c|}
\hline (3) Attri & tes of $P$ & Road.shp & & & & - & $\square \times$ \\
\hline Shazpe & $/ \theta$ & Ficart nambe & Typex of & 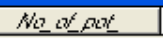 & 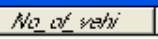 & Wiactiz 2 Lf & \\
\hline PolyLine & 0 & Bosso Road & Dua-carrage & 12 & 38 & 12 meters & $\Delta$ \\
\hline PolyLine & 0 & Western by pass & Single lane & 24 & 22 & 6 meters & \\
\hline PolyLine & 0 & Kateren Gwari Road & Single lane & 45 & 27 & 6 meters & \\
\hline PolyLine & 0 & Sabon Gari road & Single lane & 23 & 19 & 6 meters & \\
\hline PolyLine & 0 & Old Airport road & Single lane & 35 & 12 & 6 meters & \\
\hline Pqlul ine & $n$ & KIנta Rnad & Sinnle lane & 25 & 9 & Fimeters & $\vec{\nabla}$ \\
\hline
\end{tabular}

Fig. 4: Attributes of road database Source: Authors' work

\section{Conclusion and Recommendations}

The study was carried out to explore and demonstrate the use and the efficacy of GIS and Remote Sensing Technologies in road monitoring. Remote sensing imageries showing the roads in the study area were used. Ground truthing was done to verify locations and features. The satellite images were georeferenced. Then the roads were extracted from the imageries and displayed as an overlay. These data were imported into the GIS and combined with the data base created. With these, the roads could be monitored, queried, etc.

The end result of the study is a system developed for monitoring of roads and planning for possible prompt maintenance. It is a system that can show where there are damages to roads that require repairs or maintenance. The study has shown that remote sensing and GIS can be used to monitor roads effectively.

The integration of satellite image and other road data collected from field measurements, maps, etc. into GIS environment, makes it possible to monitor the roads and assess their conditions. Where damages are detected, prompt maintenance can be planned and carried out because the locations of such will be clearly shown or known from the satellite images based on the analysis.

1. Remote sensing and Geographic Information Systems are modern techniques that we need to use for monitoring our roads and to plan for prompt maintenance and are recommended for government agencies and corporate organizations engaged in road design and maintenance.

2. Road database should be updated regularly.

\section{References}

[1]. Akomolafe, D. T., Adekayode, F. O., Gbadeyan, J. A., and Ibiyemi, T. S. (2009) :Enhancing Road Monitoring and Safety through the use of Geospatial Technology.International Journal of Physical Sciences, Vol. 4(5), pp. 343 - 438.May 2009.

[2]. Egunjobi, L. (1991), "Road Transport and the underdeveloped status of the Oyo North region in Nigeria". The courier No. 125, 108pp. (CDL).

[3]. Horner, S. (1991) "Roads" Dossier. The courier No.128, 108pp. Community Development Library (CDL).

[4]. Langunzad, L.V. and Mcpherson, K. (2003), GIS Applications for Road Network of The Philippines: A new Technology in Road Management. In journal of the Eastern Asia Society for Transportation Studies, volume 5, October 2003.pp. 846-854

[5]. Yu, J., Wu, T., and Yi, M., (2007), Research and Implementation of Road Monitoring GIS System. Geoinformatics 2007: Geospatial Information Technology Applications.Edited by Peng Gong, Yong xue Liu, Proceedings of SPIE Vol. 6754, 6754OQ 